\title{
Acute Cholecystitis
}

National Cancer Institute

\section{Source}

National Cancer Institute. Acute Cholecystitis. NCI Thesaurus. Code C35152.

Acute inflammation of the gallbladder. 